\title{
Correction to: Ethnomathematics in Action
}

\author{
Milton Rosa and Cristiane Coppe de Oliveira
}

\section{Correction to:}

Milton Rosa, Ethnomathematics in Action, https://doi.org/10.1007/978-3-030-49172-7

This book was inadvertently published with incorrect affiliation of Dr. Cristiane Coppe de Oliveira in the front matter (page iv and xiii), chapter 4 (page 57) and chapter 13 (page 229).

The affiliation has now been updated as follows:

Campus Universitário Pontal, Universidade Federal de Uberlândia, Ituiutaba, Minas Gerais, Brazil.

\footnotetext{
The updated online version of this book can be found at https://doi.org/10.1007/978-3-030-49172-7_4 https://doi.org/10.1007/978-3-030-49172-7_13 https://doi.org/10.1007/978-3-030-49172-7
} 